\title{
The Role of Photonics and Natural Curing Agents of TGF- $\beta 1$ in Treatment of Osteoarthritis
}

\author{
Ehsaneh Daghigh Ahmadi, Tehmeena Israr Raja, Seyed Ali Khaghani, \\ Chin Fhong Soon, Masoud Mozafari, Mansour Youseffi, Farshid Sefat
}

\begin{abstract}
Osteoarthritis $(\mathrm{OA})$ is a degenerative disease leading to the breakdown of the hyaline cartilage between a varieties of diarthrodial joints such as the knee joint, carpals of the wrist and etc. When the cartilage is affected by trauma or wear and tear, Osteolysis may occur; broken debris of cartilage found within the synovial fluid may be recognised as a pathogen and therefore, the body's autoimmune response will directly target the cartilage for destruction. Cytokines are proteins/peptides of glycoproteins that are secreted by cells and are involved in interaction and communication between cells. Transforming Growth Factors Beta 1 (TGF- $\beta 1$ ) is one of well-known cytokines and had shown many effects on cellular biology including simulation or inhibition of cell proliferation, differentiation, production of extracellular matrix (ECM), remodelling, and producing both hormones and growth factors. On the other hand, Photonics recently play an important role for treatment of OA. The main aim of this review article is to investigate the effect of TGF- $\beta 1$ in treatment of OA. Other important aim of this work is to explore the broad applications of optics and photonics in biomedical applications including treatment of OA. Biomedical applications of photonics have broad aspects including laser, carbon nanotubes (CNTs), quantum dots (QDs) and graphene and photodynamic therapy (PDT) which discussed in this review paper.
\end{abstract}

Keywords: TGF- $\beta 1$; Cytokines; Osteoarthritis; Photonics; Carbon Nanotubes; Quantum Dots; Photodynamic Therapy. 


\section{Introduction}

\subsection{Osteoarthritis}

Osteoarthritis $(\mathrm{OA})$ is a progressive degenerative disease, which includes reduction of cartilage thickness between two bones in a joint, causing painful bone-to-bone contact. OA affects over 8 million people in the UK alone [1]. Overtime, the articular cartilage continues to degrade, reducing shock absorbance, leading to painful bone-to-bone contact [2]. When degradation of the cartilage occurs, the water retention properties are reduced due to the breakdown of the 3D matrix; as the hyaline cartilage has not access to vital lymphatics other than through diffusion and it also lacks blood vessels, healing and repair cannot occur [1]. This conveys that when degradation of the cartilage occurs, regeneration is not possible ergo a replacement is needed for one to continue with day-to-day activities. By fabricating degradation of articular cartilage under laboratory conditions, one can monitor and manipulate various factors in order to fully comprehend how the collagen matrix enables the retention of water and how other factors may influence the regrowth of cartilage [2]. Tables 1 and 2 demonstrated below convey both the surgical and non-surgical existing treatments for osteoarthritis, emphasizing the need for further study within this field [3].

\subsection{The Relevance of TGF-ß}

TGF- $\beta$ works by stimulating synthesis of proteoglycans and collagen type II alongside downregulating catabolic enzymes, which may degrade cartilage. A catabolic reaction of Interleukin one works by suppressing the synthesis of proteoglycans however, research suggests TGF- $\beta$ plays a role in counteracting this reaction ergo temporarily protecting the cartilage from further damage [4-6]. There are two categories of TGF- $\beta$ including anti-inflammatory and pro-inflammatory cytokines based on the circumstances in which they are present [7]. There are currently five different known isoforms of TGF- $\beta$ (1-5). TGF- $\beta 1$ is known to suppress anabolic cytokine production by inhibiting macrophages alongside counteracting interleukin 1,2 and $6[3,8]$.

\section{Table 1 - Non-Surgical Treatments of Osteoarthritis [3]}

\begin{tabular}{lll}
\hline Name of treatment & & \multicolumn{1}{c}{ Functionality expansion } \\
\hline $\begin{array}{l}\text { Drug use- Painkillers } \\
\text { (analgesics) including }\end{array}$ & - & Targets the PNS in order to prevent pain signals being conducted to the brain. \\
non-steroidal Anti- & - & Targets the CNS to ensure the brain doesn't recognise the pain signals being conducted. \\
inflammatory drugs & - & $\begin{array}{l}\text { Examples include paracetamol, aspirin and Ibuprofen. } \\
\text { (NSAID's) }\end{array}$
\end{tabular}

Drug use- Steroidal Anti- _ - $\quad$ Uses steroids to target the effected joint, reducing local inflammation.

inflammatory drugs _ - These drugs contain Cortisone, which is known to cause long-term damage to the liver, therefore are not the preferred choice of treatment [3].

Physiotherapy $\quad-\quad$ Uses exercise to increase the mobility of the joint to aid in cartilage repair.

- May cause an increase of GAG production however cartilage is irreparable therefore this cannot be considered a cure 
Table 2 - Surgical Treatments of Osteoarthritis

\begin{tabular}{l} 
Name of treatment \\
\hline Arthroplasty
\end{tabular} $\begin{aligned} & \text { Functionality expansion } \\
& \text { A form of joint replacement (total or partial) } \\
& \text { This treatment wastes healthy tissue as when osteoarthritis occurs, only the cartilage } \\
& \text { is damaged; arthroplasty would remove the majority of the joint including healthy } \\
& \text { tissue, hence why is not seen as an appropriate treatment. } \\
& \text { Pnes joint }\end{aligned}$

Figure 1. Example of total knee replacement arthroplasty [9].

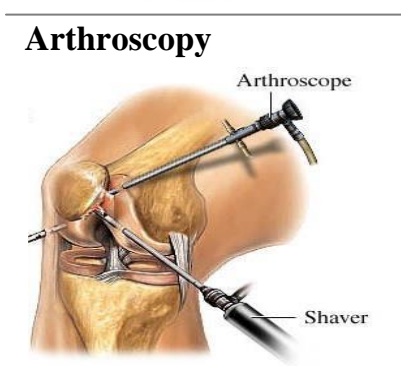

- $\quad$ Removal of loose cartilage present in the inflamed synovial capsule via the use of an arthroscope and shaver in order to reduce inflammation and increase mobility.

- May cause other issues such as blood clots, infection, and threat of dislocation as a result of a loose joint.

Figure 2. Example of total knee replacement arthroplasty [9].

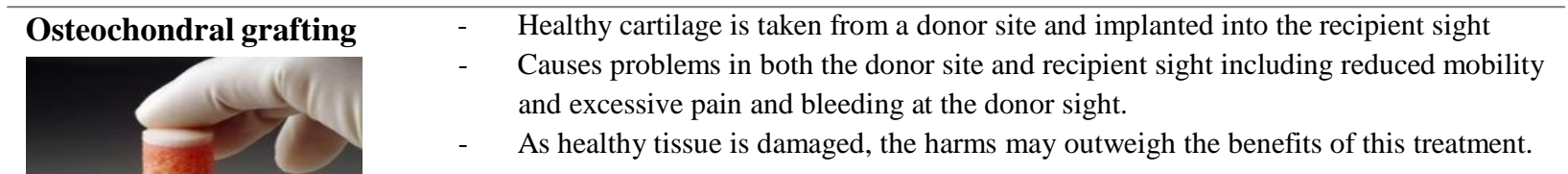

Figure 3. Displays exemplary healthy tissue inclusive of bone and cartilage taken from donor site.

\subsubsection{Osteoarthritis and TGF- $\beta 1$}

OA effects the entire joint structure (inclusive of the articular cartilage, subchondral bone and synovium tissue); in osteoarthritis, during the early stages, the cartilage surface is still intact but some minor fibrillations can be seen [10]. When this sign is present, chondrocytes react by proliferation, which causes cell clusters to be formed. The superficial zone also displays fibrillations leading to chondrocytes being lost. Slowly, the fibrillations transform into fissures extending into the mid zone, the cartilage begins to erode, the bone surface begins to wear and finally deformation occurs [11]. For osteoarthritis in particular, there are multiple factors including a higher rate of pro-inflammatory cytokines, examples including TNF and interleukin, chemokines and degradation enzymes (MMP's, aggrecanases) which are suspected to effect progressive cartilage loss by activating an inflammatory signal leading to apoptosis [10]; TGF- $\beta 1$ is thought to reduce the effects of these cytokines.

Latest research on transgenic mice studies point out that TGF- $\beta$ signalling pathways play a critical and unique role in chondrocytes during the development of osteoarthritis, and progress by driving chondrocytes toward hypertrophy, encouraging osteo-progenitor cell differentiation into osteoblasts alongside stimulating fibrosis [12]. It is a perceived fact that large amounts of TGF- $\beta 1$ are present in healthy cartilage however in the samples of cartilage on which osteoarthritis has had its effect, TGF- $\beta 1$ content is lower in quantity; this fact being supported by the research of renowned scientists worldwide [13-26]. In order to further support these findings, an experiment was carried out where naïve murine knee joints were injected with the TGF- $\beta 1$. The effect of this action was an observed increase in proteoglycan content [4]. In addition, when the same experiment was carried out on a sample of rheumatoid arthritis 
cartilage samples, it was found that the growth factor had indeed ensured the cartilage was sheltered from extensive loss of proteoglycans [27].

\subsubsection{The Role of TGF-ß1 in Pathophysiology}

Towards the end of the 1980's, TGF- $\beta 1$ had shown many effects on cellular biology, whether it be simulation or inhibition of cell proliferation, alongside inflection of cell growth, differentiation, production of ECM, remodelling, and producing both hormones and growth factors. It was also discovered within this time that other major biological responses and diseases effected by the transforming growth factor included its effects on wound healing and fibrosis, inhibiting proliferation, promotion of chemotaxis, and regulation of apoptosis, differentiation and immune cell function [28].

Soon after looking into TGF- $\beta 1$, it became evident that additional isoforms and other related growth factors had significant effects on the changes in human physiology. It was found that the TGF- $\beta 1$ family could be distinguished from other growth factor groups via the identification of signalling; the TGF- $\beta 1$ family signal through the transmembrane serine- threonine kinase receptors. Furthermore, the majority of cells may express this growth factor. The responses to this growth factor family may differ greatly depending on the manner in which the receptors are expressed at the surface of the cell, the proteins which are activated/regulated from the receptors, and the secondary pathways which are active within the relevant cell alongside the transcriptional complexes which are being made in the nucleus. Combined, the overall effect is that depending on the differing cells and contexts, various differing genes and signalling responses are either activated or repressed, responding to the signal expressed by the growth factor.

Cytokines are proteins/peptides of glycoproteins that are secreted by cells and are involved in interaction and communication between cells. The regulation of proteoglycan metabolism has been affected by a variety of growth factors, one known as TGF- $\beta 1$. This is an anabolic cytokine, which controls mainly cell differentiation and proliferation (rapid growth of cells) [7]. In terms of articular cartilage, TGF- $\beta 1$ can be produced by osteoblasts and osteoclasts. It is said to have both pro and anti-inflammatory properties, which is why observing the presence of TGF$\beta 1$ on degraded cartilage is considered a topic of great interest. TGF- $\beta 1$ has also been known to kill $\mathrm{T}$ cells, which attack our tissue, alongside promoting wound healing by simulating matrix protein synthesis and decreasing degradation. If the presence of TGF- $\beta 1$ shows effect retaining components from the ECM or even possibly reproducing some of the damaged components, it could essentially provide a key light in curing degenerative diseases such as osteoarthritis.

\subsubsection{TGF-ß1 and ECM}

TGF- $\beta 1$ plays a critical part in cell attachment, migration, invasion, wound healing and fibrosis. This growth factor regulates the makeup of the ECM alongside the adhesive interactions between cells and the matrix in a large variety of cell type [28]. The ability derives from the unique control that TGF- $\beta 1$ has though cell type specific regulation of protein expression within the matrix; it has been known to induce the expression of fibronectin, collagens and other glycoproteins [28].

Not only the growth factor simulate cells in order to make ECM proteins, but it also regulates the expression of proteins, which are involved in the degradation of these proteins by reducing the production of the enzymes, which are present during degradation, contradictory to its ability to induce the expression of various proteases. Although it seems to have conflicting effects depending on the context of the cell and nature of regulated protease expression, the overall effect is to inhibit the ECM from degrading [28]. By preventing degradation of the ECM, glycosaminoglycans (GAGs), a key hydrophilic element located within chondrocytes will not be lost; with osteoarthritis being a degenerative disease, the fact that TGF- $\beta 1$ is rumored to prevent degradation, confirms that retention of GAGs is possible [28]. TGF- $\beta 1$ also affects adhesion and interaction of cells with the matrix due to its additional ability to regulate adhesion receptors, which are known to cause mediation between cell interaction and ECM proteins [29]. 


\subsubsection{TGF- $\beta 1$ Signaling Pathways}

TGF- $\beta 1$ works by signalling through a couple of receptors (TGF- $\beta$-RI (ALK5) and TGF- $\beta$-RII.) When the type 2 receptor is bound to the growth factor, it can recruit and add the type I receptor to a phosphate group, thereby activating the SMAD receptors. The SMAD receptors respond to TGF- $\beta$ signaling [30]. Normalisation of cell proliferation, differentiation and death occurs as an effect of SMAD (II, III, IV) proteins transducing signals from TGF- $\beta$ superfamily ligands; activating the receptor serine/threonine kinases. SMADs 6 and 7 however may prevent TGF- $\beta$ signaling due to their inhibitory nature [31].

Development of complexes with the mediating Co-SMAD (common mediating SMAD) occurs as an effect of phosphorylation of receptor-activated SMADs (R-SMADs) before they are moved to the nucleus for the TGF- $\beta$ responsive genes are transcribed [31]. ALK's are activing receptor like kinases, type I for TGF- $\beta$. The SMAD 1, 5 and 8 pathways are used to signal the ALK 1, 2, 3 and 6. The SMAD 2 or 3 pathways are used to signal the ALK 4, 5 and 7. With chondrocytes in particular, TGF- $\beta$ is known to signal through ALK 1, thereby activating the SMAD 1, 5 and 8 pathways during the differentiation stage [11].

A study was carried out in which it was predicted that interleukin intervention caused a lack of response to the TGF$\beta 1$ counteraction by down regulating SMAD 2 and 3 receptors alongside upregulating inhibitory SMAD receptors. [31]. Davidson et al found this research a topic of interest and further conducted a study on mice to observe PG synthesis after being exposed to anabolic cytokines and further induced with TGF- $\beta 1$ [31]. It was found that less chondrocytes were present which expressed TGF- $\beta 1$ receptors in the cartilage of mature mice. SMAD expression was unaffected, but then again SMAD2 phosphorylation was reduced with age. It can therefore be hypothesized from this research that the decreased TGF- $\beta 1$ counteraction of IL- 1 caused impairment to the chondrocytes present in the cartilage of mature mice because it had instigated a general reduction in TGF- $\beta 1$ signalling capacity [31].

Joint diseases including osteoarthritis and rheumatoid arthritis may be effected by the presence of TGF- $\beta 1$. They are both characterised by the decomposition of the AC, resulting loss of joint function. In osteoarthritic joints at the synovial tissue, excessive Proinflammatory cytokine IL-1 can be detected, alongside many forms of TGF- $\beta 1$ and BMPs; the roles in that state are not clearly understood [28]. It is assumed that the presence of excessive TGF- $\beta 1$ in patients suffering from rheumatoid arthritis is to protect the site from undergoing further damage via inhibition of macrophages and $\mathrm{T}$ cell proliferation. It has been proven that functional TGF- $\beta 1$ signalling in overexpressed TGF- $\beta 1$ (in murine cells) protects lymphoid cells from development of rheumatoid arthritis alongside counteracting the destructing activity of the IL 1 by downregulating expression of the IL-1 receptor [28].

\subsubsection{Problems Associated with Utilizing TGF-ß1}

Adverse effects of administrating large amounts of TGF- $\beta 1$ to a knee joint were found when adenoviral transfection was used to administer amounts of more than $20 \mathrm{ng}$ of TGF- $\beta 1.20 \mathrm{ng} / \mathrm{ml}$ is most definitely considered a satisfactory amount in order to continue collagen deposition, and when more than this amount is administered, the result ensures chondro-osteophyte formation [31]. The formation of osteophytes additionally narrows the space between the joint and bone leading to painful bone-to-bone contact and loss of function for the cartilage. In osteoarthritis, osteophytes mature in diarthrodial joints at the site of the joint capsule. The cells involved in the formation of osteophytes are present in the periosteum and the synovial lining within the capsule; osteophytes are formed from mesenchymal stem cells [32]. Osteophytes change the structure of the cartilage, weakening the resistance to compression of the joint. Many scientists have concluded that formation of osteocytes are indeed present and connected with cartilage that has been subjected to trauma [31-33]. The mesenchymal precursor cells derive the osteophytes during the differentiation process and it has been found in multiple studies that by inducing excessive amounts of TGF- $\beta 1$, (more than $20 \mathrm{ng} / \mathrm{ml}$ ), osteophytes will more than likely be induced.

Mesenchymal cells are stromal cells known to differentiate into other cell types; two main linages of mesenchymal differentiation include osteoblast and chondrocyte linages. The signalling of this specific growth factor with respect given to osteogenic and chondrogenic differentiation (which drives skeletal development) was studied. It was shown 
that BPM's induce bone formation, promote mesenchymal cell commitment to osteogenic fate alongside inducing osteocyte apoptosis. TGF- $\beta 1$ regulates each stage of chondrocyte, osteoblast and osteoclast differentiation [28]. TGF$\beta 1$ unfortunately cannot regulate commitment of mesenchymal stem cells to the osteoblast linage as it fails to convert c2c12 myoblast cells into osteoblast completely differentiated [28]. On the other hand, however, it does play a role in simulation of causing proliferation of osteoblast progenitors; acting as a chemoattractant for these cells, it becomes clear as to why these progenitors are present in high amounts at the fracture sites around which TGF- $\beta 1$ has been released $[28,34,35]$.

\section{Applications of Photonics in Cartilage and Bone Treatment}

In addition to the broad applications of optics and photonics in optoelectronics devices [36-40], recently they have increasingly become applicable in biomedical applications such as surgery [41], sensing [42], photodynamic therapy [43-44], photothermal therapy [45-46] and nanoscale imaging [47]. Biomedical applications of photonics have broad aspects including laser, carbon nanotubes (CNTs), quantum dots (QDs), graphene and photodynamic therapy (PDT).

\subsection{Laser}

Laser, light amplification of by stimulated emission of radiation, plays a crucial role in biomedical and dental and orthopedic applications of photonics [48]. Laser technology has long traditional surgical applications for about 40 years, few years after the invention of $\mathrm{CO}_{2}$ laser by C. Kumar N. Patel in 1964 [49-51]. Today different types of lasers such as $\mathrm{CO}_{2}(10,600 \mathrm{~nm})$ [52], Nd:YAG $(1,064 \mathrm{~nm})$ [53], Er:YAG $(2940 \mathrm{~nm})$ [54,55] and Ar (514 nm) [56] lasers have become a promising tool in medical applications. Research achievements of short-pulsed infrared laser systems, during the late 1980s and 1990s, had opened up a new window for the laser applications in bone and dental hard substances [57]. The best bone ablation results are corresponded to the laser systems operating in wavelengths of 2.9, 3, and 5.90-6.45 $\mu \mathrm{m}$ absorbed by biological hard tissue [58]. Following to this investigation, Er:YAG $(2.94 \mu \mathrm{m})$, Er,Cr:YSGG $(2.78 \mu \mathrm{m})$ and $\mathrm{CO}_{2}$ lasers seemed to be the most effective candidate for the purpose of cutting mineralised tissue [59-62] and hard-tissue ablation [63]. Generally reducing the operating time and complications of surgeries are benefited by laser application in surgery [64].

Laser Induced Breakdown Spectroscopy (LIBS) is another application of laser in medical applications and it enables real-time tissue identification for tissue specific ablation, for example differentiation between cartilage tissue and cortical bone tissue [65]. Specifically, in cartilage and bone tissue surgery, another concern is to provide enough information of what kind of tissue is being ablated at the bottom of the cut while laser is utilised in order to prevent iatrogenic damage of structures. As an example, in the temporomandibular joint (TMJ), the main goal of a surgery is specific ablation and shaping of diseased cartilage, bone or synovial tissue and also extensive removal of MTJ structures; while LIBS provides enough information via real-time tissue observation [65].

\subsection{Carbon Nanotube (CNT)}

In addition to laser, CNT is another promising biomaterial candidate for the purpose of tissue regeneration in orthopedic [66], dental implants [67 and ex-vivo biosensing [68]. CNTs exists as multiwall or single wall metallic/semiconductor hollow cylinder with diameter of 0.2-7 nm; while the lengths are typically micrometers. Unique optical, mechanical, electrical and thermal properties of CNTs as well as their functionalisation capability and biocompatibility make them impressive capacity in biomedical applications such as scaffold for bone tissue engineering, dental implant and drug delivery systems [69-74]. In regard to the unique mechanical properties of CNTs, low fracture toughness and fragility of hydroxyapatite which has been largely used for maxillofacial surgery and orthopedic/dental implant can be compensated by adding single wall carbon nanotubes (SWCNTs) to the hydroxyapatite structure (HY-SWCNTs) and it will become more resistant with enhanced biocompatibility [75-78]. Furthermore, HY-SWCNTs could increase the bone formation as well as speed up the bone-healing process in diabetics suffered from a lower bone growth [79,80]. In orthopedic therapy, observation of the healing sites of the bone and detection of bone-related diseases are also challenging and important issues. Among other materials, CNTs 
bone sensors are promising candidates due to their excellent electrical and mechanical properties $[81,82]$; as bone regeneration accelerates under electrical conduction [83].

Another application of CNTs is to facilitate human bone marrow mesenchymal stem cell (MSC) chondrogenesis [84,85] due to its mechanical properties. Despite bone which has a self-repairing tissue, cartilage has a low regenerative capacity. Recent study demonstrated that MSC chondrogenesis is enhanced by electrospinning 3D biomimetic nanostructured scaffold based on hydrogen treated MWCNTs and biocompatible poly (L-lactic acid) (PLLA) polymer [84]. Importantly, this study showed that mechanical strength and a compressive Young's modulus of scaffolds significantly increased and matched to natural articulate cartilage ( 0.75-2 MPa depending on location) [86-89] while the MWCNTs embedded scaffolds were utilised compared to a pure PLLA ones and it is due to the superlative mechanical properties of CNTs [84]. Notably, there is no an adverse effect on cellular activity was observed while there is a dramatic enhancement on mechanical strength [84].

\subsection{Quantum Dots (QDs)}

In addition to CNTs, QDs, nanoscale semiconductor devices where electrons and holes are spatially confined in three dimensions, are also promising biomaterial candidates in biomedical applications [90-97] as well as optoelectronic applications [98-103]. From a physical point of view, semiconductor QDs exhibiting atomic-like discrete energy levels are of great interest in a wide range of applications from light-emitting diodes [99] and solar cells [101,102] to fluorescence tags for biomedical imaging [93-96] due to their unique optical and electrical properties and high quantum efficiency. QDs were first discovered by Alexey Ekimov in 1981 initially published in Russian language and then published in English in 1982 [104,105] and after less than two decades in 1998, their first biomedical applications as ultrasensitive biological detectors [106] and fluorescent biological labels were reported [107]. QDs nanoparticles are great candidates which allow real-time observation of bone regeneration and feature healing due to the unique optical properties and high quantum efficiency. Human bone marrow-derived mesenchymal stem cells (hMSCs) have exceptional bone regenerative potential, while QD attachment to hMSCs allow to monitor the cell regeneration under confocal microscope [108]. In this study, MC3T3-E1 osteoblast cells attached to the biocompatible hydroxyapatite (HA) were fluorescently labelled using hydrophilic CdSe/ZnS QDs as nanoparticles which allow direct observation of bone growth [108].

\subsection{Photodynamic Treatment (PDT)}

PDT is another aspect of photonics applications in clinical treatments. In PDT, highly cytotoxic singlet oxygen $\left({ }^{1} \mathrm{O}_{2}\right)$ produced by light absorption of photosensitiser destroy the cancer cells or modify molecules and cell organelles which are close to the sites of formation of singlet oxygen [109-114]. The photosensitiser light absorption, the penetration depth of excitation light into tissue and the availability of tissue oxygen are main factors affected on PDT efficiency. The excitation light wavelength is also depending on the medical purpose of PDT; for example, a short wavelength excitation is applied in order to maximise the penetration depth while a long wavelength excitation is utilise to limit the penetration depth and to avoid exposing the deeper healthy tissue. In terms of the biological compatibility, maximum optical transparency and deep tissue penetration can be utilised by near-infrared (NIR) photosensitization enabling the remote treatment and also thick tumor [115]. In addition to the cancer treatment, PDT can also be utilised to activate the TGF- $\beta 1$ which is one of the main bone growth factors thought the oxidative mechanism [116]. Disks of bovine articular cartilage were photosensitized by incubation with a chlorin-succinylated polylysine conjugate and irradiated with $1-2 \mathrm{~J} / \mathrm{cm}^{2}$ red light $\left(\lambda_{\max }=671 \mathrm{~nm}\right)$. These two-steps regimen dramatically inhibited IL-1-stimulated proteoglycan degradation and concomitantly increased latent and active TGF- $\beta 1$ in culture medium [116]. 


\section{References}

[1] Sophia Fox, A.J. (2009) The basic science of articular cartilage: structure, composition, and function. Sports Health, 461-468.

[2] Buckwalter, J.A. (1995) Degenerative joint disease. Clin Symp, 47(2), 1-32.

[3] Khaghani, S.A. (2010) Cell and tissue engineering of articular cartilage via regulation and alignment of primary chondrocyte using manipulated transforming growth factors and ECM proteins. Bradford: University of Bradford.

[4] Van Beuningen, H.M. (1993) Protection from interleukin 1 induced destruction of articular cartilage by transforming growth factor beta: studies in anatomically intact cartilage in vitro and in vivo. Ann Rheum Dis, 185-190.

[5] Smith, P. (2000) Genetic enhancement of matrix synthesis by articular chondrocytes: comparison of different growth factor genes in the presence and absence of interleukin-1. Arthritis Rheum, 43.

[6] Takahashi, N.R.K. (2005) Elucidation of IL-1/TGF-beta interactions in mouse chondrocyte cell line by genome-wide gene expression. Osteoarthritis Cartilage, 426-438.

[7] Jun-Ming Zhang, J.A. (2007) Cytokines, Inflammation and Pain. Int Anesthsion Clin., 45(2), 27-37.

[8] Roberts, AB.S.M. (1993) Physiological actions and clinical applications of transforming growth factor-beta (TGF-beta). Growth Factors, 1-9.

[9] Total Knee Replacement (2014) Retrieved from Krames Stay Well: https://api.kramesstaywell.com/Content/ebd5aa86-5c85-4a95-a92aa524015ce556/medical-illustrations/Images/pmuscsk20140310v0005.jpg

[10] Mariani, L.P. (2014) Signaling Pathways in Cartilage Repair. International Journal of Molecular Sciences, 8668-8669.

[11] Davidson, A. B. (2009) TGF-beta signaling in chondrocyte terminal differentiation and osteoarthritis. Experimental Rheumatology and Advanced Therapeutics, 1539-1545.

[12] Shen, J. (2014) TGF- $\beta$ signaling and the development of osteoarthritis. Bone Research.

[13] Sefat, F. (2014) Transforming Growth Factor Beta (TGF- $\beta$ ): Natural Curing Agents for Repair, MOJ Cell Sci Report 1(3):00009.

[14] Raja, T.I., Khaghani, S.A., Zafar, M.S., Khurshid, Z., Mozafari, M., Youseffi, M., Sefat, F. (2017) Effect of TGF- $\beta 1$ on Water Retention Properties of Healthy and Osteoarthritic Chondrocytes. Materials Today Procedia.

[15] Sefat, F., Youseffi, M., Khaghani, S.A., Soon, C.F., Javid, F. (2016) Effect of Transforming Growth Factor- $\beta 3$ on mono and multilayer chondrocytes, Cytokines, 83:118-26.

[16] Sefat, F., Khaghani, S.A., Nejatian, T., Genedy, M., Abdeldayem, A., Salehi Moghadam, Z., Denyer, M.C.T., Youseffi, M. (2015) Transforming Growth Factor Beta (TGF- $\beta$ ) Isomers Influence Cell Detachment of MG-63 Bone Cells, Tissue and Cells, 47, 567-574.

[17] Sefat, F., Denyer, M.C.T., Youseffi, M. (2014) Effects of Different Transforming Growth Factor Beta (TGF- $\beta$ ) Isomers on Wound Closure of Bone Cell Monolayers, Cytokines, 64, 75-86.

[18] Beggs, C.B., Denyer, M.C.T., Lemmerz, A., Sefat, F., Wright, C., Youseffi, M. (2010) The effect of transforming growth factor beta (TGF$\beta 3$ ) and Sanicle on wound healing, Proceedings of the World Congress on Engineering (WCE): International conference of systems biology and bioengineering (ICSBB), 2010, June 30th -July 2nd, London, UK, Vol II, pp 572-577, (ISBN: 978-988-17012-9-9).

[19] Sefat, F., Youseffi, M., Berends, R.F., Khaghani, S.A., And Denyer, M.C.T. (2009) The Effect of Transforming Growth Factor Beta (TGF$\beta 3$ ), $\mathrm{HCl}$ and $\mathrm{BSA} / \mathrm{HCl}$ on Trypsinisation of Bone Cells Monolayer, Proceedings of the World Congress on Engineering (WCE): International conference of systems biology and bioengineering (ICSBB), 2009, July 1 - 3, London, UK, Vol II, 1859-1862 (ISBN:978-988-18210-1-0).

[20] Sefat, F., Youseffi, M., Berends, R.F., Khaghani, S.A., And Denyer, M.C.T. (2009) The Anti-Scarring (Wound Closure) Properties of TGF$\beta 3, \mathrm{BSA} / \mathrm{HCl}$ and $\mathrm{HCl}$ in Cultured Human Bone Cell Monolayer, Proceedings of the World Congress on Engineering (WCE): International conference of systems biology and bioengineering (ICSBB), 2009, July 1 - 3, London, UK, Vol II, 1866-1871.

[21] Khaghani, S.A., Sefat, F., Youseffi, M., Rehman,R., Soon, C.F., Akbarova, G. (2016) Effect of transforming growth factor- $\beta$ on up/down regulation of integrin- $\beta 1$ in primary chondrocyte culture. European Cells and Materials, TCES, August 2016, UCL, London, UK.

[22] Khaghani, S. A., Denyer, M.C.T., Youseffi, M., Berends, R.F., Sefat, F., Lobo, S., And Javid, F.A. (2009) Purification of Primary Chondrocyte Cells isolated from articular joint using neonate Sprague-Dawley Rats, presented at the Winter meeting of Anatomical Society of Great Britain \& Ireland (ASGBI): The Art of Anatomy, St Anne's College, Oxford, UK, 6th - 8th January 2009; J. Anat.215, 711-712.

[23] Khaghani, S. A., Denyer, M., Sefat, F., Youseffi, M. (2008) Alignment of rat primary chondrocyte cells to Collagen type-I, Fibronectin and Laminin, Presented at the Winter meeting of Anatomical Society of Great Britain \& Ireland (ASGBI): A symposium on Anatomy and Matters Forensic, St Anne's College, Oxford, UK, 3rd - 4th January 2008; J. Anat.213, 351.

[24] Pedrozo HA, S. Z. (1988) Growth plate chondrocytes store latent transforming growth factor TGF- $\beta 1$ in their matrix through latent TGF- $\beta 1$ binding protein-1. J Cell Physiol, 343-354.

[25] Redini F, M. W. (1997) Differential expression of membrane-anchored proteoglycans in rabbit articular chondrocytes cultured in monolayers and in alginate beads. Effect of transforming growth factor- $\beta 1$.Biochim Biophys Acta, 20-32.

[26] Morales T.I. (1991) Transforming growth factor- $\beta$ in calf articular cartilage organ cultures: synthesis and distribution. Arch Biochem Biophys, 397-405.

[27] Glansbeek H.L. (1988) Stimulation of Articular Cartilage Repair in Established Arthritis by Local Administration of Transforming Growth Factor- $\beta$ into Murine Knee Joints. Lab Invest, 133-142.

[28] Derynck, R. (2008) The TGF- Beta Family. New York: Cold Spring Harbor Laboratory Press.

[29] Hynes, R. (1987) Integrins: A family of cell surface receptors. Cell, 549-555.

[30] Scharstuhl, V.B. (2002) Loss of transforming growth factor counteraction on interleukin 1 mediated effects in cartilage of old mice. Ann Rheum Dis, 1095-1098.

[31] Davidson, B. (2005) Reduced transforming growth factor-beta signaling in cartilage of old mice: role in impaired repair capacity. Arthritis Res Ther, R1338-R1347.

[32] Van der Kraan, P.M (2007) Osteophytes: relevance and biology. OsteoArthritis and Cartilage, 237-240.

[33] Bakker A.C. (2001) Overexpression of active TGF-beta-1 in the murine knee joint: evidence for synovial-layer-dependent chondro-osteophyte formation. Osteoarthritis Cartilage., 128-136.

[34] Sefat, F (2013) Cell engineering of human bone, Scholars' Press, Lambert Academic Publishing, Germany, ISBN: 978-3-639-51674-6.

[35] Sefat, F (2013) Bone Cells and Mechanical Stimulation, Scholars' Press, Lambert Academic Publishing, Germany.

[36] Sarpkaya, I., Daghigh Ahmadi, E., Shepard, G.D., Mistry, K.S, Blackburn, J.L., Strauf, S. (2015) Strong Acoustic Phonon Localization in Copolymer Wrapped Carbon Nanotubes, ACS Nano 9 (6), 6383.

[37] Luxmoore, I.J., Daghigh Ahmadi, E., Wasley, N.A., Fox, A.M., Tartakovskii, A.I., Krysa, A.B., Skolnick, M.S.S. (2010) Control of Spontaneous Emission from InP Single Quantum Dot in GaInP Photonic Crystal Nanocavities, Applied Physics Letters 97, 181104.

[38] Luxmoore, I.J., Daghigh Ahmadi, E., Luxmoore, B.J., Wasley, N.A., Tartakovskii, A.I., HUGUES, M., Skolnick, M.S., Fox, A.M. (2012)

Restoring Mode Degeneracy in H1 Photonic Crystal Cavities by Uniaxial Strain Tuning, Applied Physics Letter 100, 121116.

[39] Luxmoore, I.J., Daghigh Ahmadi, E., Fox, A.M., Hugues, M., Skolnick, M.S. (2011) Unpolarized H1 Photonic Crystal Nanocavities 
Fabricated by Stretched Lattice Design, Applied Physics Letters 98, 041101. 
[40] Luo, Y., Daghigh Ahmadi, E., Shayan, K., Ma, Y., Mistry, K.S., Zhang, C., Hone, J., Blackburn, J.L., Strauf, S. (2017) Purcell-enhanced quantum yield from carbon nanotube excitons coupled to plasmonic nanocavities. Nature Communications 8:1413, 1-9.

[41] Carsten. M., Mario, A. (2015) Lasers in surgery. Photonics \& Lasers in Medicine, Volume 4, Issue 3.

[42] Fan, X. (2008) Sensitive optical biosensors for unlabeled targets: A review Analytica Chimica Acta, Volume 620, Issues 1-2, 8-26.

[43] Sitterley, V.B., Nishimutaz, J.F., Levenstonz, M.E. (2009) Photochemical approaches for bonding of cartilage tissues, Osteoarthritis and Cartilage, 17, 1649-1656.

[44] Lawrence, G., Sullivan, A., Tayyaba Hasan, B., Wright, M., Henry, J., Towle, C.A. (2002) Photodynamic treatment has chondroprotective effects on articular cartilage, Journal of Orthopaedic Research 20 (2002) 241-248.

[45] Yasuhiko, H. (2014) Photothermal ablation of tumor cells using a single-walled carbon nanotube-peptide composite. Journal of controlled release 173: 59-66.

[46] Prashanti, J. (2013) Accelerated killing of cancer cells using a multifunctional single-walled carbon nanotube-based system for targeted drug delivery in combination with photothermal therapy. International journal of nanomedicine 8: 2653.

[47] Ntziachristos, V. (2005) Looking and listening to light: the evolution of whole-body photonic imaging, Nature Biotechnology 23, 313-320.

[48] Najeeb, S., Khurshid, Z., Zafar, M.S., Ajlal, S. (2016) Applications of Light Amplification by Stimulated Emission of Radiation (Lasers) for Restorative Dentistry.

[49] Patel, C.K.N. (1964) Interpretation of $\mathrm{CO}_{2}$ optical maser experiments. Phys Rev Lett; 12:588. Erratum in Phys Rev Lett; $12: 684$.

[50] Rao, M.C. (2013) Applications of $\mathrm{CO}_{2}$ laser in medicine. IJAPBC; 2(3):501-6.

[51] Ha, R.Y., Burns, J.L., Hoopman, J.E., Burns, A.J. (2003) Lasers in plastic surgery. SRPS;9(40):1-27.

[52] Okada, M., Shimizu, K., Ikuta, H., Horii, H., Nakamura, K. (1987) An alternative method of vascular anastomosis by laser: Experimental and clinical study. Lasers Surg Med; 7:240-248.

[53] Jain, K.K. (1984) Sutureless extra-intracranial anastomosis by laser. Lancet; 2:816-817.

[54] Zajak, A. (2004) Electrooptically Q-switched mid-infrared Er:YAG laser for medical applications, Optics Express, 12, 21, 5125-5130.

[55] Skorczakowski, M. (2010) Mid-infrared Q-switched Er:YAG laser for medical applications, Laser Phys. Lett. 7, 7, 498-504.

[56] White, R.A., White, G.H., Fujitani, R.M., Vlasak, J.W., Donayre, C.E., Kopchok, G.E., Peng, S.K. (1989) Initial human evaluation of argon laser- assisted vascular anastomoses. J Vasc Surg; 9:542-547.

[57] Stübinger, S. (2010) Advances in bone surgery: the er:YAG laser in oral surgery and implant dentistry, Clinical, Cosmetic and Investigational Dentistry, 2: 47-62.

[58] Peavy, G.M., Reinisch, L., Payne, J.T., Venugopalan, V. (1999) Comparison of cortical bone ablations by using infrared laser wavelengths 2.9 to 9.2 microm. Lasers Surg Med. 25(5):421-434.

[59] Bader, C., Krejci, I. (2006) Indications and limitations of Er:YAG laser applications in dentistry. Am J Dent. 19(3):178-186.

[60] Bornstein, E.S., Lomke, M.A. (2003) The safety and effectiveness of dental Er:YAG lasers. A literature review with specific reference to bone. Dent Today. 22(10):129-133.

[61] Iaria, G. (2008) Clinical, morphological, and ultrastructural aspects with the use of Er:YAG and Er,Cr:YSGG lasers in restorative dentistry. Gen Dent. 56(7):636-639.

[62] Convissar, R.A. (2004) The biologic rationale for the use of lasers in dentistry. Dent Clin North Am. 48(4):771-794.

[63] Tulea, C.A., Caron, J., Gehlich, N., Lenenbach, A., Noll, R., Loosen, P. (2015) Laser cutting of bone tissue under bulk water with a pulsed pslaser at $532 \mathrm{~nm}$, Journal of Biomedical Optics 20(10), 105007.

[64] Boulnois, Jean-Luc. (1986) Photophysical processes in recent medical laser developments: a review. Lasers in Medical Science 1.1: 47-66.

[65] Mehari, F., Christian, M., Knipfer, C., Kanawade, R., Klämpfl, F., Adler, W., Stelzle, F. Schmidt, M. (2014) Laser induced breakdown spectroscopy of bone and cartilage differentiation - ex vivo study as a prospect for a laser feedback mechanism, Biomed Opt Expres 5(11), 4013. [66] Sitharaman, B. (2008) In vivo biocompatibility of ultra-short single-walled carbon nanotube/biodegradable polymer nanocomposites for bone tissue engineering. Bone 43, 362-370.

[67] Khang, D., Park, G.E., Webster, T.J. (2008) Enhanced chondrocyte densities on carbon nanotube composites: the combined role of nanosurface roughness and electrical stimulation. J. Biomed. Mater. Res. A 86, 253-260.

[68] Heller, D.A. (2009) Multimodal optical sensing and analyte specificity using single-walled carbon nanotubes. Nature Nanotech. 4, 114-120.

[69] Martins-Júnior, Paulo Antônio. (2016) Bone Repair Utilizing Carbon Nanotubes. Bioengineering Applications of Carbon Nanostructures. Springer International Publishing, 1-15.

[70] Malarkey, E.B., Parpura, V. (2010) Carbon nanotubes in neuroscience. Acta Neurochir Suppl 106:337-341.

[71] Mattson, M.P., Haddon, R.C., Rao, A.M. (2000) Molecular functionalization of carbon nanotubes use as substrates for neuronal growth. J Mol Neurosci 14(3):175-182.

[72] Chang, T.M., Prakash, S. (2001) Procedures for microencapsulation of enzymes, cells and genetically engineered microorganisms. Mol Biotechnol 17(3):249-260.

[73] Hartgerink, J.D., Beniash, E., Stupp, S.I. (2001) Self-assembly and mineralization of peptide-amphiphile nanofibers. Science 294(5547):16841688.

[74] Maeda, H., Sawa, T., Konno, T. (2001) Mechanism of tumor-targeted delivery of macromolecular drugs, including the EPR effect in solid tumor and clinical overview of the prototype polymeric drug SMANCS. J Control Release 74(1-3):47-61.

[75] Curtin, W.A., Sheldon, B.W. (2004) CNT-reinforced ceramics and metals. Materials Today 7:44-49.

[76] White, A.A., Best, S.M., Kinloch, I.A. (2007) Hydroxyapatite-carbon nanotube composites for biomedical applications: a review. Int J Appl Ceram Tec 4:1-13.

[77] Wang, W., Zhu, Y., Watari, F., Liao, S., Yokoyama, A., Omori, M. (2012) Carbon nanotubes/hydroxyapatite nanocomposites fabricated by spark plasma sintering for bonegraft applications. Appl Surf Sci 262:194-199.

[78] Choi, J.W., Kong, Y.M., Kim, H.E. (1998) Reinforcement of hydroxyapatite bioceramic by addition of Ni3Al and Al2O3. J Am Ceram Soc 81(7):1743-1748.

[79] Sá, M., Andrade, V., Mendes, R., Caliari, M., Ladeira, L., Silva, E. (2013) Carbon nanotubes functionalized with sodium hyaluronate restore bone repair in diabetic rat sockets. Oral Dis 19 (5):484-493.

[80] Mishima, N., Sahara, N., Shirakawa, M., Ozawa, H. (2002) Effect of streptozotocin-induced diabetes mellitus on alveolar bone deposition in 
the rat. Arch Oral Biol 47(12):843-849.

[81] Newman, P., Minett, A., Ellis-Behnke, R., Zreiqat, H. (2013) Carbon nanotubes: their potential and pitfalls for bone tissue regeneration and engineering. Nanomedicine, 9(8):1139-1158.

[82] Lin, Y., Taylor, S., Li, H. (2004) Advances toward bioapplications of carbon nanotubes. J Mater Chem. 14(4):527-541.

[83] Supronowicz, P.R., Ajayan, P.M., Ullmann, K.R., Arulanandam, B.P., Metzger, D.W., Bizios, R. (2002) Novel current-conducting composite substrates for exposing osteoblasts to alternating current stimulation. J Biomed Mater Res., 59(3), 499.

[84] Holmes, B., Castro, N., Li, J., Keidar, M., Zhang, L.G. (2013) Enhanced human bone marrow mesenchymal stem cell functions in novel 3D cartilage scaffolds with hydrogen treated multi-walled carbon nanotubes, Nanotechnology 24, 365102.

[85] Garg, T., Singh, O., Arora, S., Murthy, R. (2012) Scaffold: a novel carrier for cell and drug delivery, Crit. Rev. Ther. Drug Carrier Syst. 29,

[86] Cui, X., Breitenkamp, K., Finn, M.G., Lotz, M. D’Lima, D.D. (2012) Direct human cartilage repair using three-dimensional bioprinting technology, Tissue Eng. A 18, 1304.

[87] Perera, J.R., Gikas, P.D., Bentley, G. (2012) The present state of treatments for articular cartilage defects in the knee, Ann. R. College Surgeons England 94, 381

[88] Hogervorst, T., Eilander, W., Fikkers, J.T. Meulenbelt, I. (2012) Hip ontogenesis: how evolution, genes, and load history shape hip morphotype and cartilotype, Clin. Orthop. Relat. Res. 470, 3284.

[89] Chahine, N.O., Collette, N.M., Thomas, C.B., Genetos, D.C., Loots, G.G. (2014) Nanocomposite scaffold for chondrocyte growth and cartilage tissue engineering: effect of carbon nanotube surface functionalisation, Tissue Eng. Part A. 20(17-18), 2305.

[90] Signore, M. (2008) Quantum dots for biomedical applications. Expert opinion on medical diagnostics 2.3: 315-322.

[91] Chinnathambi, S (2014) Silicon quantum dots for biological applications. Advanced healthcare materials 3.1: 10-29.

[92] Alves, L. (2010) Core-shell quantum dots tailor the fluorescence of dental resin composites. Journal of dentistry 38.2: 149-152.

[93] Li, Jingjing., Jun-Jie, Zhu. (2013) Quantum dots for fluorescent biosensing and bio-imaging applications. Analyst 138.9: $2506-2515$.

[94] Wegner, K.D., Hildebrandt, N. (2015) Quantum dots: bright and versatile in vitro and in vivo fluorescence imaging biosensors. Chemical Society reviews $44.14: 4792-4834$.

[95] Michalet, X. (2005) Quantum dots for live cells, in vivo imaging, and diagnostics. Science 307.5709: 538-544.

[96] Medintz, I.L., (2005) Quantum dot bioconjugates for imaging, labelling and sensing. Nature materials 4.6: 435-446.

[97] Cinteza, L.O. (2010) Quantum dots in biomedical applications: advances and challenges. Journal of Nanophotonics 4.1: 042503-042503.

[98] Wang, K.L. (2007) Ge/Si self-assembled quantum dots and their optoelectronic device applications. Proceedings of the IEEE 95.9: 1866-1883.

[99] Liang, R. (2014) Quantum dots-based flexible films and their application as the phosphor in white light-emitting diodes. Chemistry of Materials 26.8: $2595-2600$

[100] Konstantatos, G., Edward, H.S. (2013) Colloidal quantum dot optoelectronics and photovoltaics. Cambridge University Press.

[101] Wu, Jiang. (2014) Quantum Dot Solar Cells. Springer New York.

[102] Carey, G.H., (2015) Colloidal quantum dot solar cells. Chemical reviews 115.23: 12732-12763.

[103] Schornbaum, J. (2015) Light-emitting quantum dot transistors: emission at high charge carrier densities. Nano letters 15.3: $1822-1828$.

[104] Ekimov, A.I., Onushchenko, A.A. (1982) Quantum size effect in the optical-spectra of semiconductor micro-crystals. Soviet Physics Semiconductors-Ussr 16.7: 775-778.

[105] Ekimov, A.I., Efros, A.L., Onushchenko, A.A. (1985) Quantum size effect in semiconductor microcrystals. Solid State Communications 56.11: 921-924.

[106] Bruchez, M. (1998) Semiconductor nanocrystals as fluorescent biological labels. Science 281.5385: 2013-2016.

[107] Chan, W.C.W., Shuming, N. (1998) Quantum dot bioconjugates for ultrasensitive nonisotopic detection. Science 281.5385: $2016-2018$.

[108] Hsieh, M.F., Li, J.K., Lin, C.A. (2009) Tracking of cellular uptake of hydrophilic CdSe/ZnS quantum dots/hydroxyapatite composites nanoparticles in MC3T3-E1 osteoblast cells. J Nanosci Nanotechnol. 9(4):2758-2762.

[109] Henderson, B.W., Dougherty, T.J. (1992) Photodynamic Therapy: Basic Principles and Clinical Applications.

[110] Prasad, P.N. (003) Introduction to Biophotonics, Wiley-Interscience.

[111] Prasad, P.N. (2012) Introduction to Nanomedicine and Nanobioengineering, Wiley.

[112] Pervaiz, S., Olivo, M. (2006) Art and science of photodynamic therapy. Clin. Exp. Pharmacol. Physiol. 33, 551-556.

[113] Gupta, A. (2012) Multifunctional nanoplatforms for fluorescence imaging and photodynamic therapy developed by post-loading photosensitizer and fluorophore to polyacrylamide nanoparticles. Nanomed. Nanotechnol. Biol. Med. 8, 941-950.

[114] Ohulchanskyy, T.Y. (2007) Organically modified silica nanoparticles with covalently incorporated photosensitizer for photodynamic therapy of cancer. Nano Lett. 7, 2835-2842.

[115] Huang, Y.Y. (2010) In vitro photodynamic therapy and quantitative structure-activity relationship studies with stable synthetic near-infraredabsorbing bacteriochlorin photosensitizers. J. Med. Chem. 53, 4018-4027.

[116] Lawrence, G. (2002) Photodynamic treatment has chondroprotective effects on articular cartilage. Journal of Orthopaedic Research 20, 241248 . 